\title{
Augmented Reality Experience: Initial Perceptions of Higher Education Students
}

\section{Irfan Sural}

Asst. Prof., Eskisehir Osmangazi University, Faculty of Education, Department of Computer Education and Instructional Technology, Turkey, isural@ogu.edu.tr

The main goal of this paper is to unveil the results of survey study that intends to explore the candidate teachers' opinions about using augmented reality (AR) in classrooms. For this purpose, marker-based mobile augmented reality application has been developed and computer hardware devices are used as a teaching material. In addition, candidate teachers allowed to use this augmented reality application and share their opinions regarding to user experience. In data collection, survey and open-ended questions are used and conducted to candidate teachers in Department of Computer Education and Instructional Technology, Faculty of Education. The tools and technology required to develop a AR and development experiences are also shared. According to results teacher candidates are very excited of using augmented reality for the first time in their learning. it is also emphasized that it would be beneficial to disseminate augmented reality in their other learning materials.

Keywords: augmented reality, virtual reality, teacher's candidate, teacher education, ICT

\section{INTRODUCTION}

The use of information and communication technologies (ICT) in education and training activities continues to increase day by day. The education system has attached importance to using ICT in classrooms, and many efforts have been made to provide equipment and interactive teaching technologies in schools. Recently, one of the biggest opportunity is augmented reality. New possibilities for teaching and learning provided by augmented reality have been increasingly recognized by educational researchers. Augmented Reality is such a technology that offers a new educational approach in helping learners develop critical capacity and deeper understanding of the concepts underlying scientific investigation. Also, augmented reality makes it possible to study abstract concepts such as three-dimensional shapes and geometric objects, which are difficult to understand through a text book. Since augmented reality merges any digital information within real-world settings, i.e. electronic data or information, in a variety of

Citation: Sural, I. (2018). Augmented Reality Experience: Initial Perceptions of Higher Education Students. International Journal of Instruction, 11(4), 565-576. https://doi.org/10.12973/iji.2018.11435a 
media formats as not only visual and graphic media but also text, audio, video and haptic overlays, it has big research potential on educational settings.

AR brings truly unlimited possibilities for teaching and learning process. While AR systems are often associated with informal learning, studies explored their impact in formal education, both in primary and secondary schools (Cuendet, Bonnard, Do-Lenh, Dillenbourg, 2013). Building and using AR scenes combines active complex problem solving and teamwork to create engaging educational experiences to teach science, math or language skills, and studies have found that this activity enhances student motivation, involvement, and engagement (P. O'Shea, 2008). AR technology has an ability to render in 3D model anything that may be hardly visualized in a classroom, at a computer, in minds of students. Inverse abstract and difficult content in visual models help students get deeper understanding about lesson topic.

Therefore, this study intends to help the readers get an insight about (1) the candidate teachers' opinion about using augmented reality in classrooms, and (2) share experiences of augmented reality development processes.

\section{CONCEPTUAL FRAMEWORK}

Augmented reality is a technology that has been used in in many settings as well as in educational activities recently. Augmented reality has great potentials in education, more specifically in learning. Using this technology with its relevant tool students can learn and even build content with what they studied or understood on their subject contents. In literature, there are lots of studies that emphasize how augmented reality is used in field of health science (Moro, Štromberga, Raikos, \& Stirling, 2017), cartography and geographic information science (Carrera \& Asensio, 2017), architecture (Lee, Dünser, Kim, \& Billinghurst, 2012), cultural heritage (Kim, Matuszka, Kim, Kim, \& Woo, 2017), Simulation Training (Aebersold, et al., 2018), Astronomy (Shelton \& Stevens, 2004). Serio, Ibáñez, \& Kloos, (2013) in their study showed that augmented reality technology has a positive impact on the motivation of middle-school students. They used Keller's ARCS motivation model to gather information regarding attention, relevance, confidence, and satisfaction motivation factors. Motivational factors of attention and satisfaction in an augmented-reality-based learning environment were better rated than those obtained in a slides-based learning environment (Serio, Ibáñez, \& Kloos, 2013). Another study compared augmented reality and web interfaces for learning electromagnetism. In this study higher levels of flow were observed in students who worked with augmented reality and evaluation reports showed that better learning outcomes for augmented reality interface users (Ibáñez, Serio, Villarán, \& Kloos, 2014). In lessons that are required to understand complex concepts, to acquire knowledge through observation, imitation and participation AR can be used effectively. Although Moro, Štromberga, Raikos, \& Stirling (2017) found no significant difference observed in anatomical test scores of virtual reality, augmented reality and tabled 3D groups, they observed intrinsic benefits such as increased learner immersion and engagement.

As technology evolves from desktop to mobile learning platforms studies on augmented reality is also shift to mobile devices. Chiang, Yang, \& Hwang, (2014) proposed mobile 
augmented reality learning system to conduct inquiry - based learning activities. According to study results, students who learned with the augmented reality - based mobile learning approach showed significantly higher motivations in the attention, confidence, and relevance dimensions than those who learned with the conventional inquiry - based mobile learning approach (Chiang, Yang, \& Hwang, 2014). In mathematics and geometry education Construct3D which based on mobile collaborative augmented reality system is used. According to study results Construct3D is easy to learn, encourages experimentation with geometric constructions and improves spatial skills (Kaufmann \& Schmalstieg, 2003). A study to contextualize students' learning of an SSI on nuclear energy use and radiation pollution in an online radiation unit showed that students' perceptions of AR activity were positive. Also, another result of this study showed that SSI unit enhanced by mobile AR can improve students' learning of the science concepts (Chang, Wu, \& Hsu, 2013). A study on using augmented reality and its effects on student's cognitive load and achievement showed that cognitive load decreased as abstract information became concrete in printed books via multimedia materials in mobile augmented reality application (Kucuk, Kapakin, \& Goktas, 2016).

To develop augmented reality application, first existing tools and technologies should be considered carefully. There are lots of framework and platforms which can be used to develop augmented reality applications. Most popular SDK and frameworks are given below (Schmidt, 2017):

- Vuforia: Vuforia is popular platform used to work with augmented reality development. Android, iOS and Unity Editor are supported. Supported features are recognition of the different types of visual objects, text and environments recognition.

- EasyAR: EasyAR is free and easy to use augmented reality SDK. Android, iOS, Windows, Mac and Unity Editor are supported. Supported features are 3D object recognition, environment perception, cloud recognition, smart glass solution, App cloud packaging.

- Wikitude: Wikitude is all-in-one augmented reality SDK. Android, iOS, Smart Glasses are supported. Supported features are image recognition, 3D tracking, GEO Data, Cloud recognition.

- ARToolKit: ARtoolKit is an open source tracking library for augmented reality. Android, iOS, Linux, Windows, Mac OS and Smart Glasses are supported. Supported features are single-camera or stereo-camera camera position/orientation tracking, plugins for Unity and OpenSceneGraph, camera and optical stereo calibration.

\section{METHOD}

The purpose of this paper is to explore teacher candidates' opinions about using augmented reality in classrooms and share design steps that are followed in developing AR material. For this purpose, computer hardware pieces are selected as AR material. 


\section{Research Design}

In this study, a descriptive research design is used. Descriptive research design is a valid method for researching specific subjects and as a precursor to more quantitative studies. Descriptive research is often used as a pre-cursor to quantitative research designs which give general overview for some valuable pointers as to what variables are worth testing quantitatively (Shuttleworth, 2008). Descriptive studies are closely associated with observational studies, but they are not limited with observation data collection method. Case studies and surveys can also be specified as popular data collection methods used with descriptive studies (Jackson, 2009). In descriptive study design cross-sectional survey is used to take a snapshot of the frequency and characteristics of an AR experience in candidate teachers at a time.

\section{Participants}

The population of the study is undergraduate university students of Eskisehir Osmangazi University. The participants in this research were 82 candidate teachers at Department of Computer Education and Instructional Technology in 2017-2018 fall term, who were selected via convenience sampling technique. Convenience sampling is a specific type of non-probability sampling method that relies on data collection from population members who are conveniently available to participate in study (Saunders, Lewis, \& Thornhill, 2012). Convenience sampling is a type of sampling where the first available primary data source will be used for the research without additional requirements. In other words, this sampling method involves getting participants wherever you can find them and typically wherever is convenient.

Candidate teachers' gender distribution participating in this study is very close to each other. Number of male is $44(\% 53,66)$ and female is $38(\% 46,34)$.

The distribution of candidate teachers according to class they enrolled is shown in Figure 1 below.

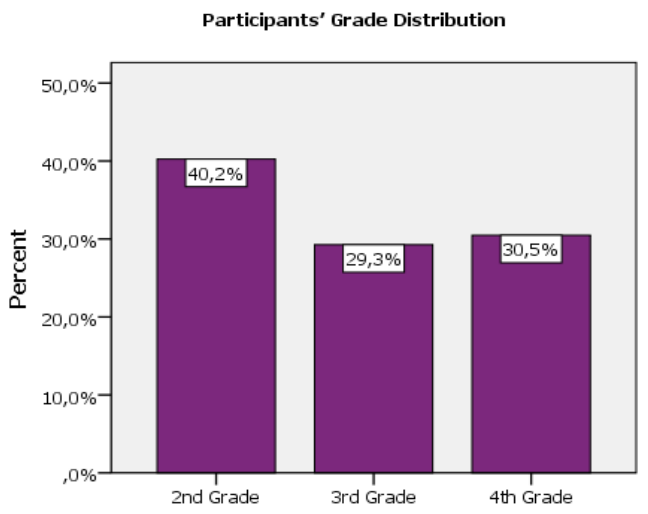

Figure 1

Grade distribution of candidate teachers 
Most of participant is attending to 2 st grade $(40,2 \%)$. It follows 4 st grade $(30,5 \%)$ and 2 st grade $(29,3 \%)$ accordingly. 1st grade students did not take part in the study because there was no new enrolment to department in the year of the study conducted.

\section{Development Process}

Marker-based augmented reality application has been developed and computer hardware pieces were used as a teaching material. Before starting to develop augmented reality application, author researched existing tools and technologies in the field. It was decided on Vuforia SDK and Unity tool which have good support and documentation. Unity is ultimate game development platform to build high-quality $3 \mathrm{D}$ and $2 \mathrm{D}$ games. In this study, Unity with Vuforia plugin was used to develop augmented reality material. First, an augmented reality based decision support system which was thought to support students in case of emergency situations like fire and earthquake was planned, but due to technical and developmental issues computer hardware pieces was selected as augmented reality material. Key components used in development process are given in Figure 2.

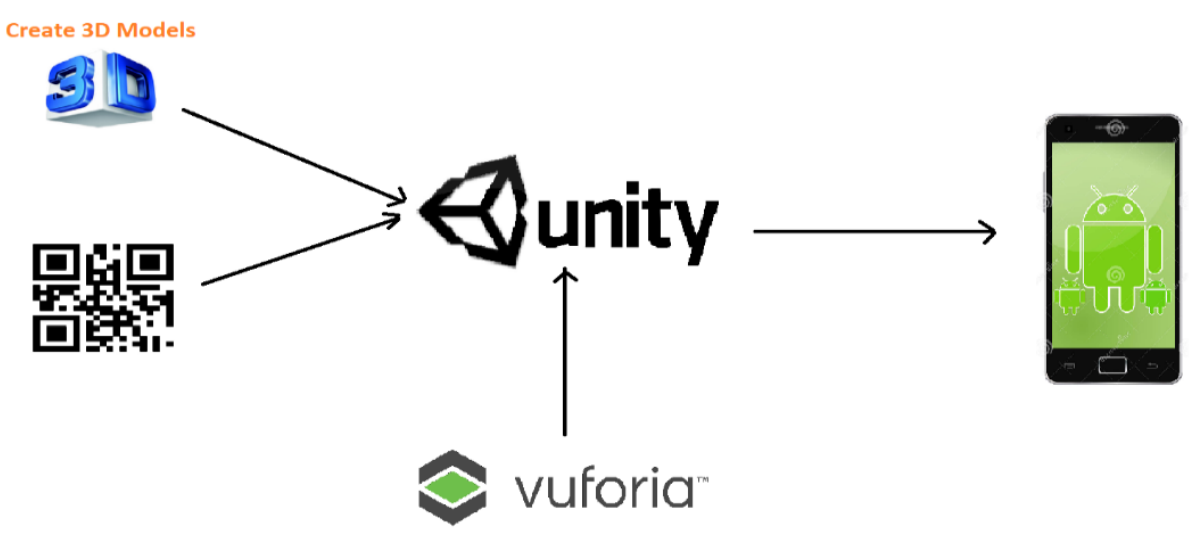

Figure 2

Augmented Reality App Development Process

3D Models: Virtual objects (created by computer i.e. video, texts or 3D computer models) is the key part in augmented reality application. The quality and functionality of objects effects the application quality and perception of usage respectively. First step in marker-based augmented reality design is developing 3D models or videos, links that can be used to show when camera scans markers.

QR Code: A QR code is a matrix barcode readable by smartphones and mobile phones with cameras (Ashford, 2010). QR codes can be created and scanned by QR readers. Most QR codes typically appears as a small white square and black geometric shapes. They are capable of coding information that ranges from web addresses to links to YouTube video, therefore in the first use of application; to download required app and settings from Play Store QR code was used. 
Vuforia: Vuforia is augmented reality extension bundled with Unity3D. Vuforia is a marker-based AR system and it enables vision detection and tracking functionality into Unity3D IDE, it also allows developers to easily create AR application and games (Santoso \& Gook, 2012).

Unity: Unity 3D is a feature rich, fully integrated development engine that provides outof-the-box functionality for the creation of interactive 3D content. Using Unity, developers can publish to multiple platforms such as PC, Web, iOS, Android and Xbox.

In development stage of mobile augmented reality, first 3D models of computer hardware pieces were prepared. Second, markers that were used to trigger 3D models were registered to database in Vuforia developer portal as shown in Figure 3.

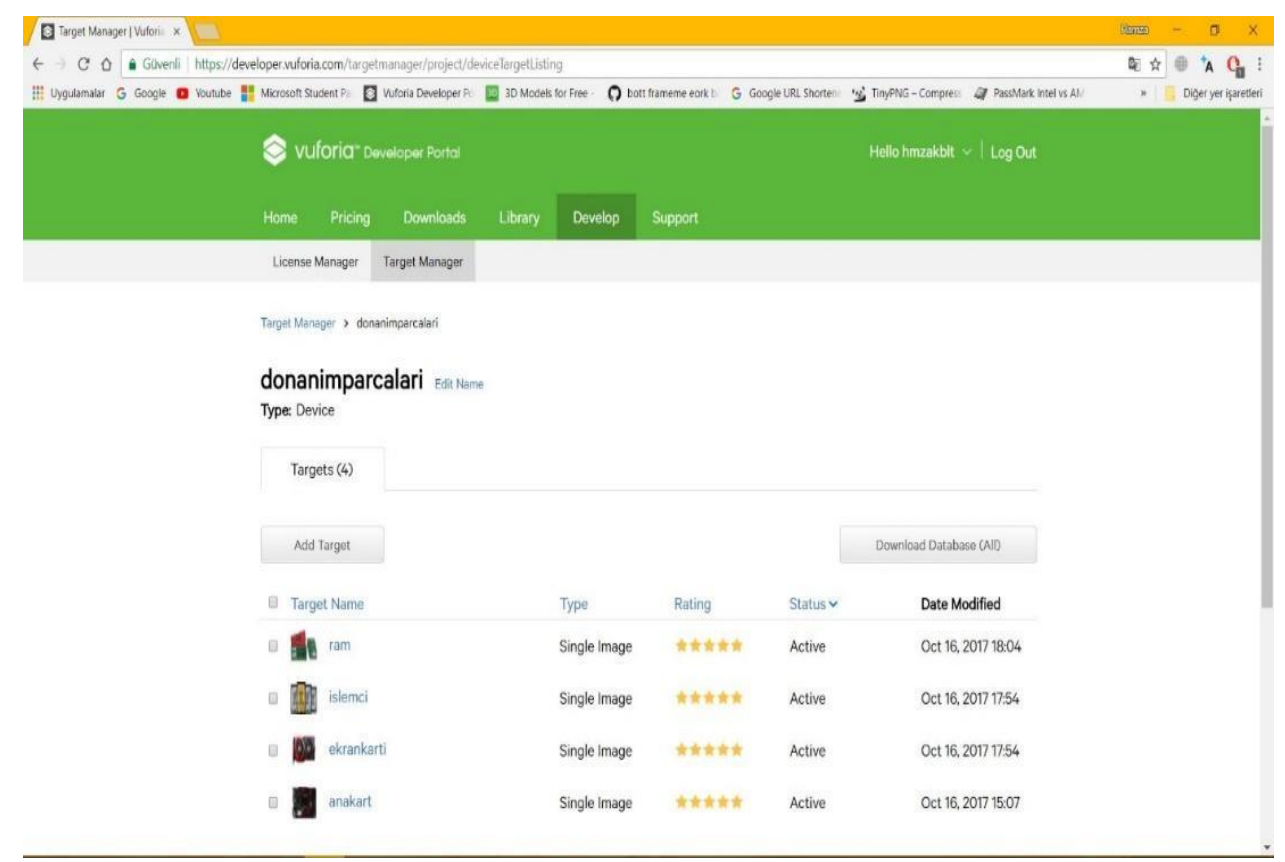

Figure 3

Registering markers in Vuforia Developer portal

This database was then downloaded and imported to Unity3D to define markers. Third, augmented reality layout was designed as shown in Figure 4.

Layout which consist of text, video and 3D model of computer hardware pieces were placed on screen and camera angles were prepared accordingly. To show text and play video at the same time, required coding at scripting editor was done. 


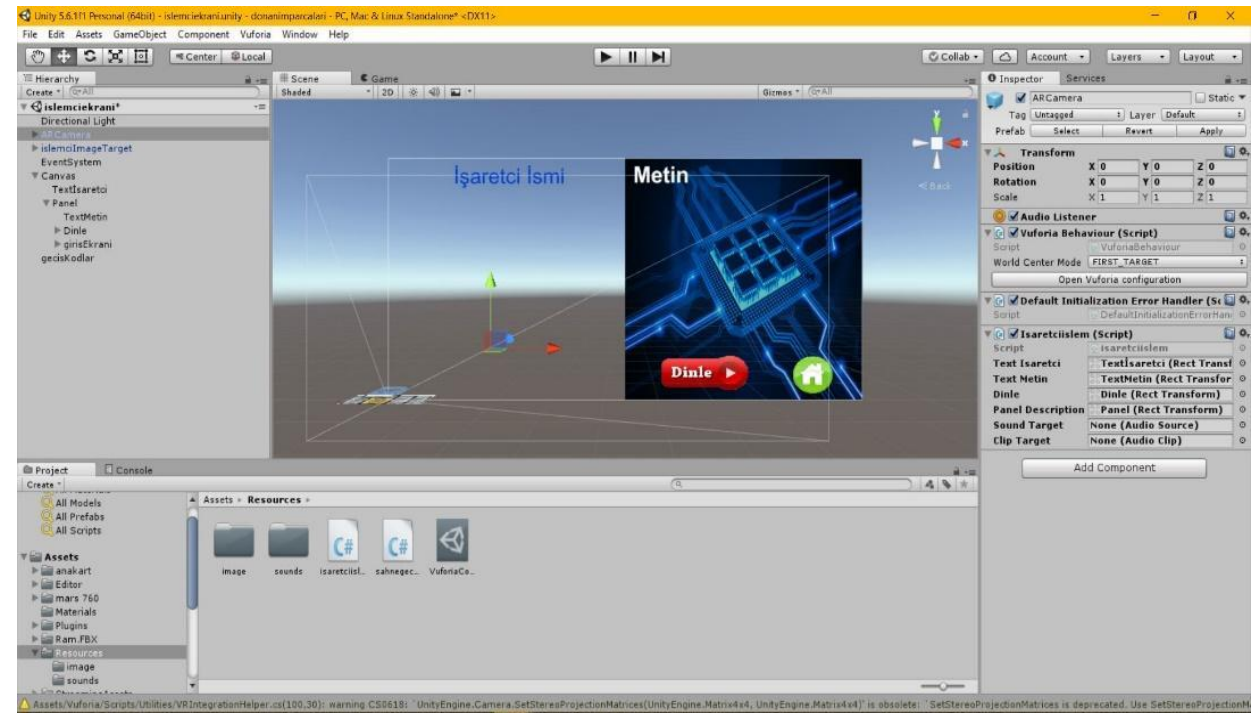

Figure 4

Augmented reality layout design

\section{Data Collection}

Augmented reality development was followed by survey questions that investigate candidate teacher opinions. The survey consisted of multiple choice, open-ended and scale type questions developed by the researcher using relevant literature review of augmented reality.

Basic descriptive questions about technology ownership and mobile augmented reality use followed by feelings and perception of candidate teachers. In a conducted survey device usage, AR knowledge, AR feelings and opinions were collected by using scale type questions. Survey questions were rated from 0-5 and 1-5 which are (for knowledge level; $0=$ none; $5=$ very good and for feelings/opinions; $1=$ strongly disagree; $5=$ strongly agree) respectively. SPSS was used to analyse data collected from survey.

To gain the validity and to avoid ambiguity, the survey questions were checked by experts in language and educational technology. The survey as well as the application was examined in the context of usefulness, attractiveness and satisfaction dimensions with field of experts. The scale type items developed to measure usefulness, attractiveness and satisfaction dimensions were prepared in this coverage. For content validity researcher sent scale type items to three experts and according to their recommendations questions were reorganized. A reliability analysis was carried out on the opinions about AR Technology values scale comprising 12 items. Cronbach's alpha showed that the scale type questions reached acceptable reliability, $\alpha=0.868$. 
Before data collection candidate teachers allowed to use AR material about 30 minutes. In this time, they downloaded AR application and used pre-printed markers to trigger AR material.

\section{Analyses of Data}

After the data collection process, the quantitative data were analysed by descriptive statics in SPSS and reported accordingly. Descriptive statistical analysis was carried out to identify the satisfaction level of using the developed AR application in learning complex materials. Open-ended question in which candidate teachers expressed their feelings and opinions about AR experience were analysed by content analyses. The basic process in content analysis is to bring the data together in a frame of specific concepts and themes, and to edit and interpret them. In addition, according to Y1ldirım and Şimşek (2013), to provide validity and reliability it is necessary to make detailed descriptions. For this purpose, the findings of the research were supported by direct quotations.

\section{FINDINGS}

To understand candidate teachers' internet usage, internet usage experience was analysed as shown in Figure 5. More than half of population have 6-10 years internet experience. On the other hand, $\% 35$ of participants have more than 10 years internet experience.

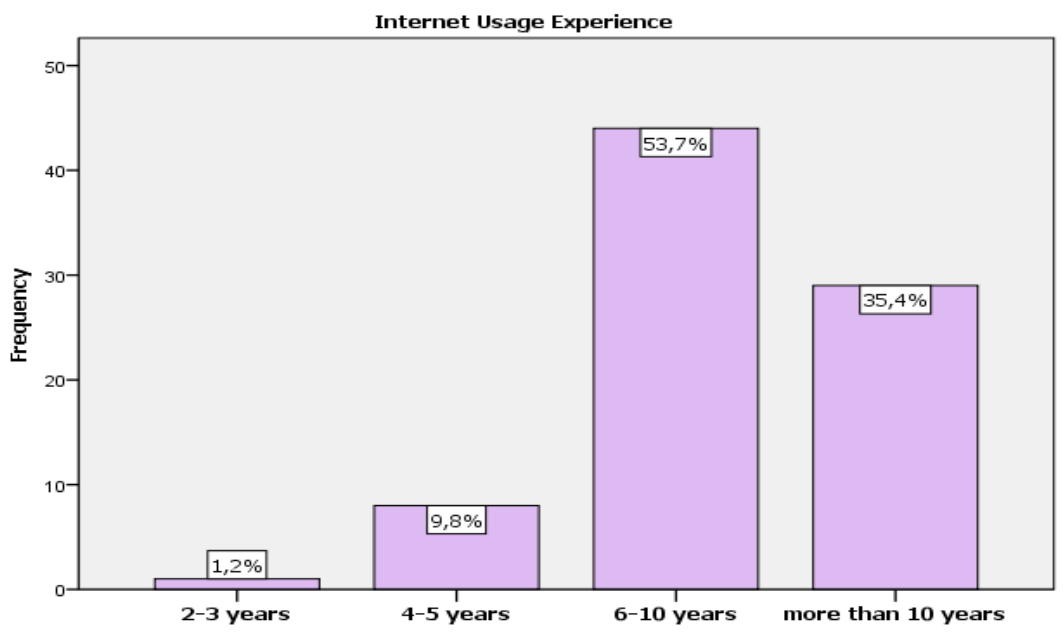

Figure 5

Candidate teachers' internet usage experience

Candidate Teachers device usage knowledge level such as desktop, laptop, tablet and smartphone is given in Table 1. 
Table 1

Device usage knowledge level

\begin{tabular}{lccc}
\hline & Total number of students & Mean & Std. Deviation \\
\hline Desktop knowledge level & 82 & 3,73 & 1,112 \\
\hline Laptop knowledge level & 82 & 3,98 &, 785 \\
\hline Tablet knowledge level & 82 & 2,60 & 1,601 \\
\hline Smart phone knowledge level & 82 & 4,35 &, 760 \\
\hline
\end{tabular}

According to analysis, the average score of participants regarding smart phone knowledge level has the highest mean score and was 4,35 ( $\mathrm{SD}=.76)$. It follows laptop knowledge level 3.98 ( $\mathrm{SD}=.785)$. The least mean score of participants is tablet knowledge level 2.60 ( $\mathrm{SD}=1.601)$. This result show us that participants mostly use smartphones as mobile device but tablet is not so common device.

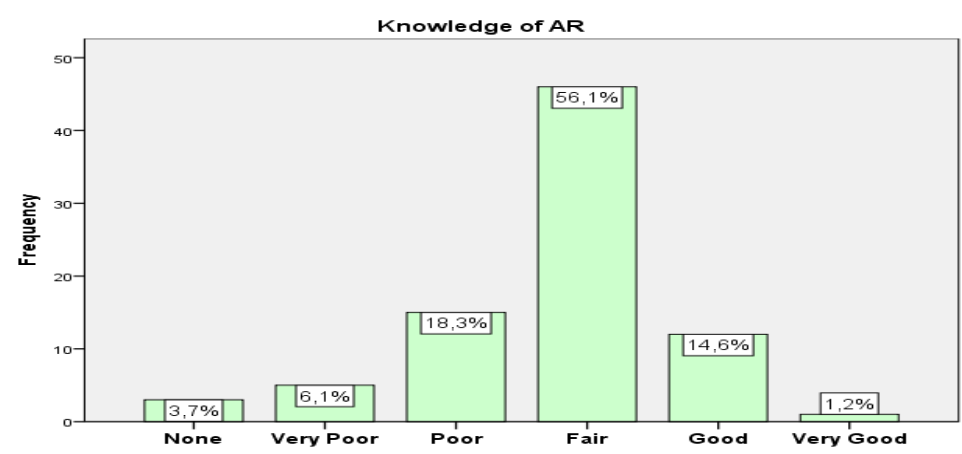

Figure 6

Knowledge of AR technology

Candidate teachers' knowledge level about AR is given in Figure 6. Most of teacher candidates have fair knowledge $(\% 56,1)$ about AR technology. It follows with poor knowledge of AR $(\% 18,3)$. This result shows us that more than half of candidate teachers have knowledge about AR in basic level.

Table 3

Opinions about AR technology

\begin{tabular}{llll}
\hline & $\mathrm{N}$ & Mean & Std. Dev. \\
\hline AR technology looks attractive & 82 & 4,67 &, 630 \\
\hline AR technology looks original & 82 & 4,45 &, 688 \\
\hline AR technology looks useful & 82 & 4,74 &, 492 \\
\hline AR technology looks satisfactory & 82 & 4,40 &, 718 \\
\hline AR Technology is flexible (study in college or in your room) & 82 & 4,59 &, 702 \\
\hline I think that the use of AR can improve spatial skills & 82 & 4,54 &, 670 \\
\hline The use of AR technology in learning seems attractive & 82 & 4,60 &, 626 \\
\hline I believe AR technology has improved my learning motivation. & 82 & 4,44 &, 739 \\
\hline The AR application created a sense of reality. & 82 & 4,39 &, 681 \\
\hline I would like learning materials to be supported with AR. & 82 & 4,65 &, 674 \\
\hline I would like to use AR applications in our courses. & 82 & 4,62 &, 780 \\
\hline I am satisfied with the applications of AR (multimedia, picture, sound, etc.). & 82 & 4,63 &, 599 \\
\hline
\end{tabular}


Candidate teachers' opinions about AR is given in Table 3 above. According to results, the average score of candidate teachers have highest mean score as $4.74(\mathrm{SD}=.492)$ in "AR technology looks useful" option. On the other hand, as the teaching material were mostly consisted of video and text, candidate teachers rated least mean score for option "AR application created a sense of reality" $4.39(\mathrm{SD}=.681)$. The developed AR material consisted of 3D models, text and audio elements. This result may be because of the AR material was not so rich as expected. Most of the AR materials should be designed in a way that students can get a sense of reality. In order to construct a high sense of reality more interactive applications should be created, too.

According to analyse results from open-ended question, candidate teachers stated that AR seems very exciting.

"First impression I found it to be fun...."

"It has increased my excitement and my desire to attend the class"

Some of the candidate teachers emphasized that AR can be useful in educational settings.

"It looks very original and useful..."

"It was very useful for course. It motivated us..."

"I think it's a useful application. If it is used in lessons, I think motivation will increase."

"When I first used the application, I was very excited and it was very interesting."

Candidate teachers indicated that AR can help students to understand abstract concepts and should be used in material design in general.

"I think it will be very useful in lessons."

"I think this kind of applications should be used in everyday life and schools immediately"

\section{DISCUSSION AND CONCLUSION}

Content is more accessible than ever but it's confined to a physical space. By using augmented reality, we can see our environments change dynamically either through a smartphone or glasses to display enhanced content and media right in front of us; it is becoming more and more available on mobile handsets and other portable devices. Findings from this research showed us that more researches and learning materials should be developed by AR and implemented in learning. To develop AR first the technology and required 3D models should be prepared and framework also should be considered accordingly.

This survey results show us that although candidate teachers have good knowledge of smartphones and laptop computers they have fair knowledge about augmented reality. Most of the candidate teachers have knowledge about the term but not in detail about the AR technology and possible use in many settings. After using augmented reality material, candidate teachers are very excited and stated that augmented reality has big potential use in teaching and learning materials. Also, they stated that they wanted to see AR technology in their lessons and learning environments. This result is very similar 
with a study done to get students' perception of the use of augmented reality (Majid, Mohammed, \& Sulaiman, 2015).

Furthermore, augmented reality should be integrated in educational settings and further research should be conducted on effectiveness of teaching and learning materials that are designed with AR enhancements.

\section{REFERENCES}

Aebersold, M., Voepel-Lewis, T., Cherara, L., Weber, M., Khouri, C., Levine, R., \& Tait, A. R. (2018). Interactive Anatomy-Augmented Virtual Simulation Training. Clinical Simulation in Nursing, 34-41.

Ashford, R. (2010). QR codes and academic libraries: Reaching mobile users. College \& Research Libraries News, 71, 526-530. Retrieved 02 01, 2018, from https://crln.acrl.org/index.php/crlnews/article/view/8454/8696

Carrera, C. C., \& Asensio, L. A. (2017). Augmented reality as a digital teaching environment to develop spatial thinking. Cartography and Geographic Information Science, 44(3), 259-270. doi:https://doi.org/10.1080/15230406.2016.1145556

Chang, H.-Y., Wu, H.-K., \& Hsu, Y.-S. (2013). Integrating a mobile augmented reality activity to contextualize student learning of a socioscientific issue. British Journal of Education Technology, 44(3), E95-E99.

Chiang, T. H., Yang, S. J., \& Hwang, G.-J. (2014). An Augmented Reality - based Mobile Learning System to Improve Students' Learning Achievements and Motivations in Natural Science Inquiry Activities. Educational Technology \& Society, 17(4), 352365 .

Creswell, J. W. (2014). Research Design: Qualitative, Quantitative and Mixed Methods Aproaches. SAGE Publications.

Cuendet S., Bonnard Q., Do-Lenh S., Dillenbourg P. (2013), Designing augmented reality for the classroom, Computers \& Education, 68, 2013, pp. 557-569

Ibáñez, M. B., Serio, Á. D., Villarán, D., \& Kloos, C. D. (2014). Experimenting with electromagnetism using augmented reality: Impact on flow student experience and educational effectiveness. Computers \& Education, 71, 1-13.

Jackson, S. L. (2009). Research Methods and Statistics: A Critical Thinking Approach 3rd edition. Belmont: CA: Wadsworth.

Kaufmann, H., \& Schmalstieg, D. (2003). Mathematics and geometry education with collaborative augmented reality. Computers \& Graphics, 27(3), 339-345.

Kim, H., Matuszka, T., Kim, J.-I., Kim, J., \& Woo, W. (2017). Ontology-based mobile augmented reality in cultural heritage sites: information modeling and user study. Multimedia Tools and Applications, 76(24), 26001-26029. 
Kucuk, S., Kapakin, S., \& Goktas, Y. (2016). Learning Anatomy via Mobile Augmented Reality: Effects on Achievement and Cognitive Load. Anatomical Sciences Education, 9(5), 411-421. doi:10.1002/ase.1603

Lee, G. A., Dünser, A., Kim, S., \& Billinghurst, M. (2012). Cityviewar: A mobile outdoor ar application for city visualization. Mixed and Augmented Reality (ISMARAMH) 2012 IEEE International Symposium (pp. 57-64). IEEE 2012.

Majid, N. A., Mohammed, H., \& Sulaiman, R. (2015). Students' perception of mobile augmented reality applications in learning computer organization. Procedia - Social and Behavioral Sciences, 176, pp. 111 - 116.

Moro, C., Štromberga, Z., Raikos, A., \& Stirling, A. (2017). The effectiveness of virtual and augmented reality in health sciences and medical anatomy. American Association of Anatomists, 10(6), 549-559. doi:10.1002/ase.1696

P. O'Shea et al., "Lessons Learned about Designing Augmented Realities," Int'l J. Gaming and Computer-Mediated Simulations, no. 1, vol. 1, 2008, pp. 1-15.

Santoso, M., \& Gook, L. B. (2012). ARkanoid: Development of 3D Game and Handheld Augmented Reality. International Journal Of Computational Engineering Research, 2(4), 1053-1059.

Saunders, M., Lewis, P., \& Thornhill, A. (2012). Research Methods for Business Students (6th ed.). Pearson Education Limited.

Schmidt, J. (2017). 8 Best augmented reality SDK for AR development for iOS and Android in 2017. Retrieved 02 06, 2018, from ThinkMobiles: https://thinkmobiles.com/blog/best-ar-sdk-review/

Serio, Á. D., Ibáñez, M. B., \& Kloos, C. D. (2013). Impact of an augmented reality system on students' motivation for a visual art course. Computers \& Education, 68, 586596.

Shelton, B. E., \& Stevens, R. R. (2004). Using coordination classes to interpret conceptual change in astronomical thinking. Proceedings of the 6th international conference for the learning sciences. Mahweh, NJ: Lawrence Erlbaum \& Associates.

Shuttleworth, M. (2008). Descriptive Research Design. Retrieved 3 20, 2018, from https://explorable.com/descriptive-research-design

Yıldırım, A., \& Şimşek, H. (2013). Soysal Bilimlerde Nitel Araştırma Yöntemleri. Ankara: Seçkin Yayıncılık. 